\section{Learning to Thrive: Building Diverse Scientists' Access to Community and Resources through the BRAINS Program}

\author{
Cara Margherio, ${ }^{* *}$ M. Claire Horner-Devine, ${ }^{\ddagger}$ Sheri J. Y. Mizumori, \\ and Joyce W. Yen" \\ †Center for Workforce Development, "College of the Environment, "Department of Psychology, \\ and "ADVANCE Center for Institutional Change, University of Washington, Seattle, WA 98195
}

\begin{abstract}
BRAINS: Broadening the Representation of Academic Investigators in NeuroScience is a National Institutes of Health-funded, national program that addresses challenges to the persistence of diverse early-career neuroscientists. In doing so, BRAINS aims to advance diversity in neuroscience by increasing career advancement and retention of post-PhD, early-career neuroscientists from underrepresented groups (URGs). The comprehensive professional development program is structured to catalyze conversations specific to URGs in neuroscience and explicitly addresses factors known to impact persistence such as a weak sense of belonging to the scientific community, isolation and solo status, inequitable access to resources that impact career success, and marginalization from informal networks and mentoring relationships. While we do not yet have data on the long-term impact of the BRAINS program on participants' career trajectory and persistence, we introduce the BRAINS program theory and report early quantitative and qualitative data on shorter-term individual impacts within the realms of career-advancing behaviors and career experiences. These early results suggest promising, positive career productivity, increased self-efficacy, stronger sense of belonging, and new perspectives on navigating careers for BRAINS participants. We finish by discussing recommendations for future professional development programs and research designed to broaden participation in the biomedical and life sciences.
\end{abstract}

\section{INTRODUCTION}

Diversity is critical to solving biomedical problems; diversity within organizations leads to superior productivity and innovation relative to homogeneous groups (McLeod et al., 1996; Milliken and Martins, 1996; Page, 2007). The nation must increase the diversity of the scientific community to enhance innovation and creative capacity and address inequities in our scientific workforce. Unfortunately, individuals from historically underrepresented racial and ethnic minorities and individuals with disabilities in academic science have higher turnover rates than individuals from well-represented groups (Milliken and Martins, 1996; Jaschik, 2014). This turnover results from a suite of challenges faced by individuals from underrepresented groups (URGs), which include blacks and African Americans, Hispanics, Native Alaskans, American Indians, Hawaiian and Pacific Islanders, and persons with disabilities. Such challenges include a weak sense of belonging to the community, isolation and solo status, inequitable access to resources that impact career success, and marginalization from both informal networks and mentoring relationships (Sandler and Hall, 1986; Wunsch, 1993; Milliken and Martins, 1996; Boice, 2000; Smith et al., 2000; Futrell and Walter, 2001; Trower and Bleak, 2004; Niemeier and Smith, 2005; Stanley and Lincoln, 2005; Nivet et al., 2008; Turner et al., 2008; Congressional Commission on the Advancement of Women and Minorities in Science, Engineering, and Technology Development, 2009; Allen-Ramdial and Campbell, 2014; Patton, 2014). Attrition during the postdoctoral and pretenure
Pat Marsteller Monitoring Editor Submitted January 16, 2016; Revised May 28, 2016; Accepted June 22, 2016

CBE Life Sci Educ September 1, 2016 15:ar49 DOI:10.1187/cbe.16-01-0058

*Address correspondence to: Cara Margherio (clm16@uw.edu).

(C) 2016 C. Margherio et al. CBE-Life Sciences Education @ 2016 The American Society for Cell Biology. This article is distributed by The American Society for Cell Biology under license from the author(s). It is available to the public under an Attribution-Noncommercial-Share Alike 3.0 Unported Creative Commons License (http://creativecommons.org/licenses/ by-nc-sa/3.0).

"ASCB®" and "The American Society for Cell Biology ${ }^{\prime}$ " are registered trademarks of The American Society for Cell Biology. 
assistant professor stage is particularly distressing, as scientists who have reached this stage have already demonstrated great talent and perseverance. Additionally, both they and the scientific community have made significant financial, professional, and emotional investments in their scientific careers.

BRAINS: Broadening the Representation of Academic Investigators in NeuroScience is a National Institute of Neurological Disorders and Stroke (NINDS)-funded, national program that seeks to address these challenges faced by individuals from URGs in one field of biomedical science: neuroscience. By offering professional and community development at the critical postdoctoral and early tenure-faculty career stages, BRAINS aims to increase the representation of individuals from URGs in neuroscience at the faculty level. BRAINS is a cohort-based program offering ongoing, community-centric professional development with a focus on catalyzing conversation specific to underrepresented minorities (URMs) in neuroscience. In this way, the BRAINS program differs from other diversity professional development programs that target specific skill development, such as grant writing (e.g., National Research Mentor Network and Early Career Institute/MINDS program; National Institutes of Health [NIH], n.d.b), development of scientific networks (e.g., Keystone Diversity Symposia), acquisition of specific scientific skills (e.g., SPINES: Summer Program in Neuroscience, Ethics \& Survival), mentoring (e.g., Society for Neuroscience's Neuroscience Scholars Program), or providing research funding support (e.g., NIH's Career Development Awards [K series; NIH, n.d.c] and Research Training and Fellowship [T and F series; NIH, n.d.a]). While research support, scientific skills, experience, and creativity are integral to a successful neuroscience career in academia, they are not sufficient. The BRAINS program focuses on enduring community-centric professional development that evolves as participants' careers change, explicitly addresses factors known to impact persistence, and targets individuals from URGs who are talented but potentially at risk of leaving science rather than individuals who seem already poised for academic career success. This paper highlights the BRAINS program theory, briefly describes the BRAINS program features, reports early signs of programmatic success on individual-level impacts, and discusses recommendations for future professional development programs for biomedical scientists from URGs.

\section{The State of Diversity for Neuroscience PhDs}

According to the U.S. Census Bureau, the percentage of individuals 25-44 years old with disabilities in 2010 was $~ 11 \%$ of the U.S. population (Brault, 2012). The estimated percentage of Hispanics 25-44 years old in the United States in 2014 was 19.2\%; of black or African Americans, 13.5\%; of American Indian or Alaska Natives, 1.3\%; and of Native Hawaiians and other Pacific Islanders, 0.3\% (U.S. Census Bureau, 2014). This diversity is not mirrored in the biomedical field workforce. A 2012 NIH report highlights limited participation by URM scientists in biomedical career training and professional development (Working Group on Diversity in the Biomedical Research Workforce, 2012). Within neuroscience, in particular, the Survey of Earned Doctorates shows that from 2001 to 2013 just 7\% (724 of 10,058) of doctorates in neuroscience or neurobiology were earned by URM U.S. citizens or permanent residents (Hoffer et al., 2002, 2003, 2004, 2005, 2006, 2007; National
Science Foundation [NSF], 2010; National Center for Science and Engineering Statistics, 2009, 2012a,b, 2014a,b). While there are no clear data on the number of neuroscientists with disabilities and their career paths, we do know that, of the 96,345 PhDs awarded from 2003 to 2012 in the biological sciences or psychology (common fields for neuroscientists), only $2 \%$ (2102 degrees) were awarded to persons with disabilities (NSF, 2004, 2007, 2009, 2011, 2013). The most recent biennial survey from the Society for Neuroscience demonstrates that the field is losing its few scientists from URGs as they move up the academic career ladder (Sved, 2013). At the next career stages (postdoctoral scientists and tenure-track faculty), the percent with URM membership declines to $\leq 5 \%$ (Sved, 2013). Therefore, it is urgent that we develop and implement strategies to stem the loss of these highly trained and skilled underrepresented neuroscientists.

\section{Beyond Scientific Skills: Social and Cultural Factors Impact Academic Persistence}

Scientific and professional skills are necessary but not sufficient to increase the persistence of a diverse neuroscience workforce. Research shows that self-efficacy (Bandura, 1977), the belief in one's ability to perform particular behaviors to produce a specific outcome, increases motivation and performance in a range of contexts and behavioral domains and is an important mediator of URMs' commitment to science (Chemers et al., 2011). In other words, an individual who believes that he or she has the ability to successfully perform the necessary tasks and skills is more likely to perform those actions in the future than an individual with the same skills but lower self-efficacy.

Social cognitive career theory (SCCT) posits that career pursuits and behaviors are influenced by career self-efficacy, outcomes expectation (beliefs about what will happen given particular behaviors), and personal goals (intention to engage in an activity to produce an outcome; Lent and Brown, 1996). When individuals have low self-efficacy, inaccurate outcome expectations, or both, they may prematurely opt out of personally rewarding careers. However, if those factors can be recalibrated, those same individuals become poised for career success in a field or occupation that seemed previously unattainable (Brown and Lent, 1996). Work with URM undergraduates in science, technology, engineering, and mathematics supports the SCCT (Lent et al., 2005; Byars-Winston and Fouad, 2008; Byars-Winston et al., 2010). According to SCCT, perceptions about potential near-term barriers and support systems are especially critical during the active phase of career decision making (Lent et al., 2000), the precise phase of BRAINS participants who are transitioning to independent careers. Interventions that illuminate and recast potential barriers and offer new support structures empower individuals to translate their goals into action and take hold of their careers (Lent et al., 2000).

In addition to self-efficacy, identity with the scientific community has been recognized as an important mediator of URMs' commitment to scientific careers (Chemers et al., 2011). Even when individuals have the requisite scientific skills, if they do not feel a sense of belonging, they may not persist in their careers (Estrada-Hollenbeck et al., 2011). Estrada-Hollenbeck et al. (2011) discuss the tripartite integration model of social influence (TIMSI), originally proposed by Kelman (1958, 2006), and demonstrate that the persistence of URM students 
in science and integration into the scientific community require not only scientific career self-efficacy and scientific identity but also an alignment of values. Because different values and cultures inform what success looks like in the academy, aligning values and navigating any differences becomes particularly salient for URM individuals, who often bridge dominant and nondominant cultures (Plaut, 2014). Such alignments have been shown to be central in shaping career interests of early-career scientists, particularly those from URGs (Gibbs and Griffin, 2013). If individuals have a limited number of faculty or peers with whom they identify or share similar values, it can be difficult for them to imagine successfully transitioning into a faculty position and to feel a sense of belonging.

\section{Impacting Persistence through Community and Conversation}

Establishing networks, mentors, and connection to a scientific community are critical for influencing self-efficacy, outcome expectations, goals, and, thus, persistence. Networking is a particularly important means of accessing information, guidance, and mentorship. Unfortunately, underrepresented scholars are often marginalized from networking activities and face systematic disadvantages to their career advancement (Sandler and Hall, 1986; Wunsch, 1993; Niemeier and Smith, 2005; Stanley and Lincoln, 2005; Nivet et al., 2008; Allen-Ramdial and Campbell, 2014). Underrepresented faculty also often have to navigate unique barriers (Nivet et al., 2008). Without an effective network of colleagues, mentors, and role models with whom they identify, feelings of isolation are exacerbated, making it even more difficult to persist.

As an individual advances through the academic landscape, it is increasingly difficult to identify a cohort of peer scientists, especially peers from URGs. Group mentoring is among the most effective contemporary approaches for decreasing the sense of isolation reported by many underrepresented faculty members working in predominantly white institutions (Jacelon et al., 2003; Fraga et al., 2010). Faculty members benefit most from a network of multiple mentors (Blackburn et al., 1981; Baugh and Scandura, 1999; Higgins, 2000; de Janasz and Sullivan, 2004). A group-mentoring model promotes community and collegiality among faculty (Boice, 1992; Tierney and Bensimon, 1996; Austin and Rice, 1998; Gappa, 2002) and encourages mutual support, benefiting all participants (Haring, 1999; Yen et al., 2006). Minority-member peer-mentoring groups have proven to effectively promote successful networking skills, increase job satisfaction, bolster retention rates, and advance URM scholars' careers (Carr et al., 2007). Further, peer-moderated mentoring groups can allow members to maintain momentum established at a formal science orientation program and address common issues such as dealing with rejection and the imposter syndrome (Milo and Schuldiner, 2009).

Beyond mentoring and networking, all trainees benefit from exposure to a wide range of examples of how to navigate an academic career. Research has shown that hearing success strategies in the context of personal stories allows individuals to gain perspective on how to navigate key transitions (Stephens et al., 2014). Such information and story sharing helps individuals discover how to align their personal values with professional opportunities and the structures of the academic workforce. Importantly, hearing such stories during important times of transition allows individuals to reimagine their futures as they enter new career stages. This type of information also allows participants to better understand the different values and cultures that inform what success looks like in the academy and how they can successfully navigate those different cultural spaces, a common challenge for faculty of color (Plaut, 2014).

Finally, catalyzing conversations specific to underserved individuals and individuals from URGs in neuroscience and academia can impact social belonging and persistence. For example, interventions for individuals from URGs that seek to normalize experiences of adversity when transitioning into new environments encourage individuals to no longer view their challenges as an indication that they do not belong but rather as part of the transition process (Walton and Cohen, 2011; Stephens et al., 2014). This perspective can lead to short-term positive outcomes, which lead to long-term effect through positive-feedback loops (Cohen et al., 2009).

The SCCT and the TIMSI theoretical frameworks suggest that interventions that connect self-efficacy, identification as scientists, and alignment of personal values with the values of the scientific and academic communities can help individuals become better integrated into the scientific community and more likely to persist and find career success in scientific fields such as neuroscience. As described in the next section, the BRAINS program was designed to impact these areas through community and conversation.

\section{METHODS}

\section{The BRAINS Program Intervention}

The BRAINS program heeds the call by Byars-Winston and colleagues to use a theoretically informed, conceptual framework when designing and executing interventions to broaden participation in science (Byars-Winston et al., 2011). Specifically, the BRAINS intervention was designed to address Betz's recommendation that, to impact self-efficacy, interventions should address Bandura's four sources of efficacy, namely, "facilitating successful performance accomplishment, providing role models (vicarious learning), social persuasion and encouragement, and teaching methods of anxiety management (physiological arousal)" (Betz, 2007, p. 415). We use the term "BRAINS program theory" to describe our conceptual framework and suggest possible mechanisms for program impacts and potential impacts over a range of timescales (Figure 1). The program theory is informed by components of the SCCT and TIMSI frameworks and positive social identity, that is, an individual's self-identification as an ethnic group member and sense of belonging to and positive regard for his or her own ethnic group (Phinney, 1992; Byars-Winston et al., 2010; see footnotes in Figure 1). While the BRAINS program has not been in existence long enough to confirm and reap the long-term individual and national impacts, this paper presents early indicators of how participation in BRAINS may result in the individual impacts on the BRAINS participants as described in the BRAINS program theory. While we do not quantitatively test the BRAINS program theory here, we present it to illustrate our conceptual framework and outline plans to examine potential causal relationships and alignments between program features and impacts when our sample size affords us the statistical power to do so (i.e., after additional cohorts). 


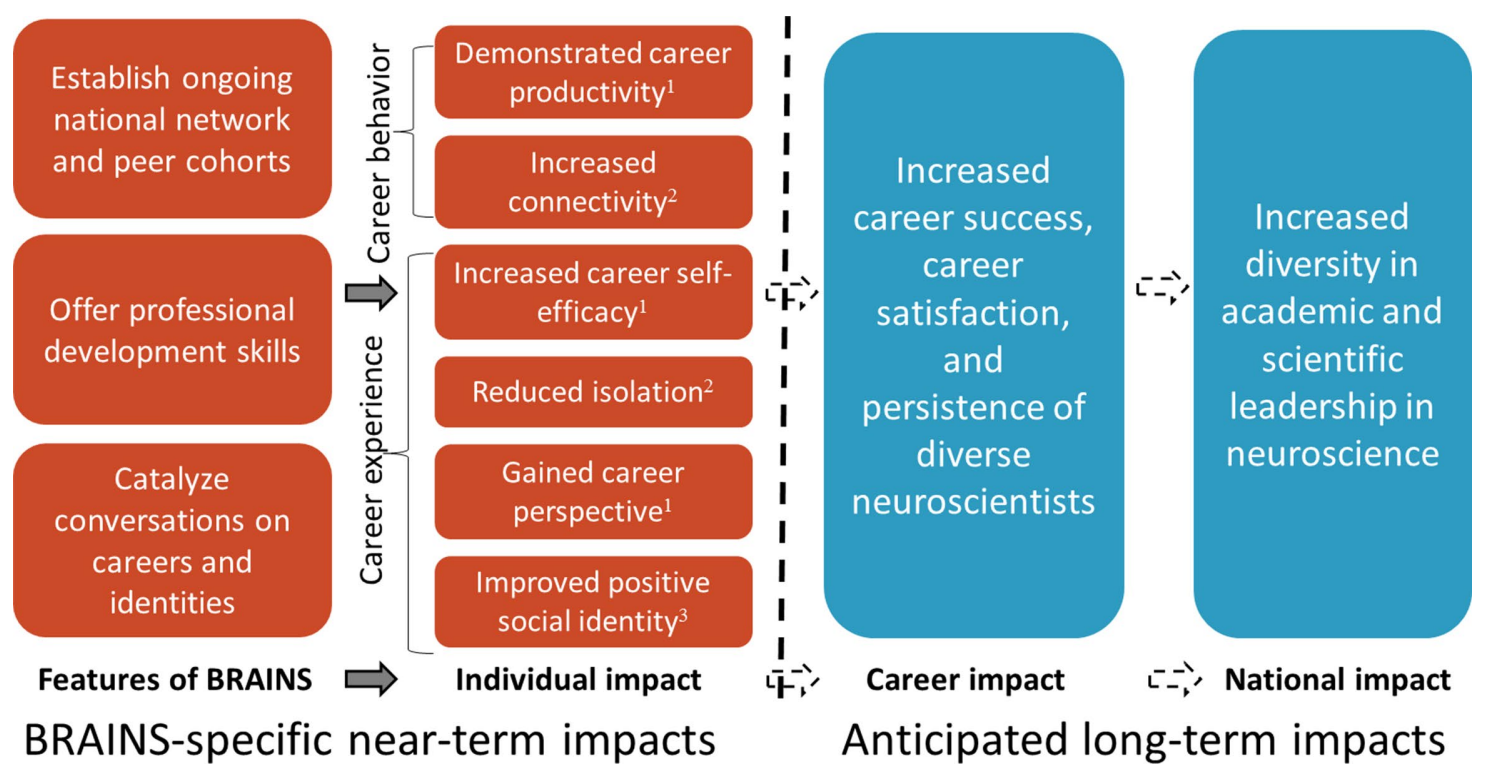

FIGURE 1. The BRAINS program theory suggests that program features may lead to short-term impacts on career behavior and experiences. We report early data related to these short-term program impacts. We anticipate that these individual impacts will lead to long-term impacts on the careers of BRAINS participants and serve to impact diversity in neuroscience at the national scale. Superscript numbers refer to social science frameworks that inform components of the model: ${ }^{1}$ SCCT, Lent and Brown, 1996; ${ }^{2}$ TIMSI, Kelman, $1958 ;$ and ${ }^{3}$ social identity, Phinney, 1992.

The design of all the elements of the BRAINS program was informed by the BRAINS program theory: a multiday national symposium, the peer-to-peer Mentoring Circles program, the Continuous Career Invention (CCI) program, and ongoing contact and support from the BRAINS program team. All BRAINS participants attended the 4-day, national symposium, which was then followed by biweekly peer-mentoring conference calls. A small subset of participants were involved in the CCI program, which consisted of three separate meetings for each participant over the course of a year and a half.

During the national symposium, the early-career scientists connected with senior scientists in highly interactive panel discussions and several skills-building workshops. While sessions addressed typical professional development topics, the symposium also emphasized community building, sharing stories, discussing social identities, and personal reflection. At each national symposium, approximately 20 senior scientists, topical experts, and BRAINS program team members provided professional and personal development support to BRAINS early-career participants. In each interactive panel discussion, senior panelists briefly shared snippets of their personal experiences on a given topic, such as navigating organizations and thriving as an only, and offered a few key tips or tools. These remarks served as discussion seeds such that the postpanel discussion was tailored to issues most relevant to that particular cohort. For example, during one of the symposia, the mastering teaching panel led to significant discussion about the different teaching experiences men and women had and how those experiences were further impacted by race. Complementing these panel sessions were expert-led topical workshops that addressed specific career skills. All sessions, panels, and skills workshops also included small-group and personal reflection activities that encouraged attendees to consider how to apply the tips to their own careers.

The national symposium was followed by the Mentoring Circles program. Each Mentoring Circle comprised six to eight early-career participants who met biweekly by audio- or videoconference. Using a structured meeting framework, Mentoring Circle conversations often focused on how to incorporate skills, strategies, and practices introduced at the BRAINS symposium into everyday life and emphasized working through an issue, rather than complaining about it. Mentoring Circles are a peerdriven mentoring model that augments traditional mentoring experiences by providing career support unencumbered by supervisory or evaluative relationships and is attentive to social science research on URMs' career needs (Williams et al., 2016).

Finally, a smaller subset of BRAINS participants took part in the CCI program. The central component of the CCI program was three "innovation and incubation" meetings, spaced 6 months apart, during which participants engaged in self-reflection, problem solving, and goal setting with a team of supportive and successful professionals who have had success in a wide range of careers. Finally, the BRAINS program staff maintained regular contact with BRAINS participants through program listservs, individual conversations and consultations, and the annual Society for Neuroscience meeting.

\section{Participants}

Two participant cohorts have entered the BRAINS program, one in January 2013 and the second in September 2014. Each cohort consists of 25-30 early-career neuroscientists who are members of URGs in neuroscience. Potential participants were recruited through a wide-reaching targeted email campaign, advertisements in neuroscience journals, a booth at the annual 
Society for Neuroscience conference, and personal contacts and word of mouth. Eligible participants were neuroscientists who had completed their PhDs and are members of groups underrepresented in neuroscience (e.g., African Americans, American Indians or Alaska Natives, Hispanics, persons with disabilities).

Interested individuals submitted an application, which included an application survey, a two-page curriculum vitae, a one-page essay describing the applicant's expectations for participating in BRAINS and his or her short- and long-term career goals, one page explaining his or her research and teaching program and interests, one or two letters of recommendation, and a letter verifying program eligibility. Applications were reviewed and ranked by two of the authors of this paper, M.C.H.D. and J.W.Y., using a rubric with nine different dimensions, including access to mentors and networks, diversity, academic potential, and applicability to funding agency's mission. The program intentionally did not select individuals who seemed already poised for academic career success. Rather, BRAINS selected for individuals who are talented but potentially at risk of leaving science due to a lack of mentoring, institutional support for career development, career satisfaction, a peer network, or other circumstances. This risk of leaving was indicated in the applications and took many forms, including feeling alone, describing the burden of being seen as representative of a whole race or gender and feeling weighed down by such expectations, questioning whether he/she wishes to remain in science even while continuing to be excited about research, and feeling overwhelmed by the prospects of navigating career transitions, particularly as an individual from a URG. In addition, this group was identified by lack of career supports through a series of questions about access and participation in professional development programs, mentoring relationships, and networks. In effect, BRAINS sought to identify individuals who have high levels of interest in academic careers and skill in neuroscience research careers but lower levels of confidence in career success (Betz, 2007), with the intention of improving their career self-efficacy and expanding their career options and, ultimately, their career success (Bandura, 1977; Betz, 2007). When possible, applications were considered for diversity; geographic and disciplinary balance to the cohort, with the goal of including participants from a range of institutions; background (race, ethnicity, ability status, age, gender, career stage); geographic location; and disciplinary interests within neuroscience.

A total of 98 neuroscientists completed the application (baseline) survey as part of the BRAINS application process ( $n=54$ in August 2012; $n=44$ in April 2014); of these applicants, 56 participated in the BRAINS program. Of the 56 BRAINS participants, 30 individuals (53.8\%) were in postdoctoral positions, while 14 individuals $(25.0 \%)$ were in tenure-track assistant professor positions at the time of application. See Table 1 for a summary of participant and nonselected applicant demographics.

\section{Survey Instruments}

The application survey, which served as the program evaluation baseline instrument, included a personal assessment of characteristics demonstrating diversity, mentoring and professional development experiences and resources, and career expectations. This online baseline survey also asked applicants to
TABLE 1. Summary of participant and applicant demographics

Participants Applicants All

\begin{tabular}{|c|c|c|c|}
\hline \multicolumn{4}{|l|}{ Disability } \\
\hline Yes & 2 & 0 & 2 \\
\hline No & 54 & 42 & 96 \\
\hline \multicolumn{4}{|l|}{ Sex } \\
\hline Female & 30 & 26 & 56 \\
\hline Male & 26 & 16 & 42 \\
\hline \multicolumn{4}{|l|}{ Hispanic } \\
\hline No & 30 & 22 & 52 \\
\hline Yes & 26 & 20 & 46 \\
\hline Mexican, Chicano & 16 & 6 & 22 \\
\hline Puerto Rican & 4 & 3 & 7 \\
\hline Cuban & 0 & 3 & 3 \\
\hline Other & 6 & 8 & 14 \\
\hline \multicolumn{4}{|l|}{ Race } \\
\hline American Indian or Alaskan Native & 4 & 0 & 4 \\
\hline Asian & 1 & 3 & 4 \\
\hline Black or African American & 29 & 19 & 48 \\
\hline Native Hawaiian or Pacific Islander & 0 & 0 & 0 \\
\hline White or Caucasian & 25 & 14 & 39 \\
\hline Other & 8 & 7 & 15 \\
\hline \multicolumn{4}{|l|}{ Position at time of application } \\
\hline Lab manager & 0 & 1 & 1 \\
\hline Postdoctoral researcher & 30 & 31 & 61 \\
\hline Research scientist & 2 & 2 & 4 \\
\hline Lead research scientist & 1 & 0 & 1 \\
\hline Lecturer & 3 & 1 & 4 \\
\hline Assistant research professor & 6 & 0 & 6 \\
\hline Assistant professor (tenure track) & 14 & 4 & 18 \\
\hline Other & 0 & 2 & 2 \\
\hline Missing & 0 & 1 & 1 \\
\hline
\end{tabular}

self-report opinions and experiences regarding their skill preparation, career goals, and professional development. BRAINS participants were also requested to complete annual follow-up surveys to track the perceived impact of the BRAINS program over time (see the Supplemental Material). On review of our human subjects minimal risk application (\#43131), the University of Washington Institutional Review Board determined this project was evaluation.

The longitudinal design of the annual surveys, coupled with the application survey, will allow assessment over time of participants' professional skill development, use of mentoring and networking, sense of belonging in the discipline, and initiative in directing one's own career path through self-reported metrics. Many studies have found evidence supporting the validity of self-reported metrics (Agho et al., 1992). Within the context of BRAINS, self-reported metrics are both reasonable and necessary to investigate self-referential perceptions such as job satisfaction, confidence, and career self-efficacy.

The initial series of BRAINS annual surveys were administered in August 2013 to the first cohort of BRAINS participants ( $n=28$ ) and in April 2015 to the second cohort of BRAINS participants $(n=28)$. Forty BRAINS participants from the first two cohorts completed the first annual survey for an overall response rate of $71.4 \%$. In this paper, we report promising early results on individual career experience and career-advancing 
behavior from the baseline survey and first annual survey for both cohorts. On both the baseline and the annual follow-up survey, self-efficacy was measured with self-reports of confidence levels on 47 separate factors. We developed these measures of self-efficacy to capture findings that emerged from qualitative survey responses of an evaluation of an earlier program similar to BRAINS. These factors were then loaded onto seven self-efficacy indices: research, management and administration, self-development, networking, mentoring, teaching and service, and fulfillment and goals. For example, the selfdevelopment self-efficacy index included factors such as "I am confident I am able to pursue a career in neuroscience or a neuroscience-related field" and "I am confident I am able to ask for help or advice when needed" among others. Two indices were calculated based on participant self-reports of careeradvancing behavior: networking activity (10 factors) and mentoring activity (14 factors). For the sense of belonging index, given the focus on faculty careers and membership in URGs in neuroscience, we were primarily interested in sense of belonging to the neuroscience research community as a member of a URG. Seven factors were included in the sense of belonging within neuroscience index, including "I regularly feel included in networks within my institution" and "I feel connected to other scientists in my research area." Although the sample size is too small to conduct factor analysis (Gorsuch, 1983; MacCallum et al., 1999), Cronbach's alpha was calculated for each index as a measure of internal consistency and reliability. As shown in Table 2, scale reliability for these indices is generally acceptable, although the management and administration index at the time of application, the sense of belonging index at the time of application, and the mentoring self-efficacy index at the time of follow-up are slightly less reliable.

Participant responses to the open-ended survey questions (such as "In what ways has the BRAINS program impacted your level of satisfaction with your career progression?" and "What practices have you changed since participating in BRAINS?") were compiled and loaded into NVivo. The program evaluator (one of the authors of this paper, C.M.) then coded the data in an iterative process using both a priori codes based on the program's goals and open coding to identify new concepts. After the first iteration of open coding to develop codes, a second iteration of closed coding was completed to ensure codes were evenly applied; this was followed by a third iteration of coding during which analytical memos and coding categories were produced. A priori codes included Isolation and solo status, Less informal networks, Marginalized from mentors, and Weak sense of belonging to neuroscience. Emergent codes included: Conflict with PI, Implicit bias of others, Lack of collaborators, and Struggles with work/life balance. These codes emerged by being repeatedly present in the data and relevant to the evolving analysis. Grounding the emergent codes and analysis within the data are one way to guard against bias (Corbin and Strauss, 1990). Analytic memos were developed on core themes and used to synthesize findings into a summary analysis. The longitudinal quantitative data analysis used Wilcoxon signed-rank tests to identify statistically significant changes over time in the indices. We then analyzed the qualitative data from the follow-up surveys to investigate the quantitative findings to identify particular programmatic interventions and innovations that may be replicated for future pro-
TABLE 2. Scale reliability of indices

\begin{tabular}{lcc}
\hline & \multicolumn{2}{c}{ Cronbach's alpha } \\
\cline { 2 - 3 } & Application & Annual survey \\
\hline Self-efficacy indices & & \\
$\quad$ Research & 0.725 & 0.908 \\
Management and administration & 0.566 & 0.806 \\
Self-development & 0.771 & 0.908 \\
Networking & 0.764 & 0.910 \\
Mentoring & 0.811 & 0.573 \\
Teaching and service & 0.800 & 0.898 \\
Fulfillment and goals & 0.739 & 0.859 \\
Connectivity and isolation indices & & \\
$\quad$ Network activity & 0.686 & 0.695 \\
Mentoring activity & 0.713 & 0.879 \\
Sense of belonging & 0.590 & 0.737 \\
\hline
\end{tabular}

fessional development programs to broaden participation in the biomedical and life sciences.

\section{RESULTS}

Baseline survey data demonstrated minimal differences between participant and nonparticipant responses. For the few statistically significant differences that did occur, the nonparticipants consistently scored higher (i.e., more confidence, more networking activity, etc.) as compared with participants at the baseline. This result is in line with the selection criteria that preferenced applicants who were promising neuroscientists at risk of leaving academic careers based on a lack of mentoring, career support and satisfaction, or peer network, or other challenging circumstances as indicated in the application essay. These early data suggest that, after participating in BRAINS, participants have productive scientific careers while showing career-advancing behavior and increased positive individual career experiences. The following results are organized by the BRAINS program theory, specifically the Individual Impact column of Career Behavior and Career Experience (see Figure 1).

\section{Impacts on Career Behavior}

According to the BRAINS program theory, BRAINS is designed to impact individuals' career behavior; we measure these individual career behaviors as career productivity (i.e., immediate job outcomes) and increased connectivity (i.e., mentoring and networking activity). To isolate the impact of the BRAINS program on career productivity, we compared changes in job position over time (from time of application to December 2015) of the BRAINS participants and nonselected applicants (Table 3). Data on current job position were obtained via Internet searches for 95 of the original applicants. Job positions were sorted into five mutually exclusive categories based on the goals of this project: 1) tenure-track neuroscience position, 2) neuroscience research position, 3) other position within neuroscience, 4) other position within a science field, and 5) no position in a science field. These categories represent the program's goal of retaining participants in neuroscience and in academia. While we did not differentiate between types of academic institutions, we did specify tenure-track positions. Utilizing these categories as outcome variables, logistic regression and multinomial 
TABLE 3. Job positions at application (August 2012 and April 2014) and in December 2015 for participants and applicants

\begin{tabular}{|c|c|c|c|c|}
\hline & \multicolumn{2}{|c|}{ Participants } & \multicolumn{2}{|c|}{ Applicants } \\
\hline & Application & December 2015 & Application & December 2015 \\
\hline Tenure-track neuroscience position & 14 & 24 & 4 & 11 \\
\hline Neuroscience research position & 39 & 19 & 32 & 19 \\
\hline Other position in neuroscience & 2 & 3 & 5 & 1 \\
\hline Other position in a science field & 1 & 7 & 0 & 6 \\
\hline No position in a science field & 0 & 1 & 1 & 2 \\
\hline
\end{tabular}

regression models revealed there were no significant differences in job outcomes between participants and nonselected applicants while controlling for demographic variables (unpublished data). We consider this a significant positive outcome of the program. Given the program's selection process, we expected to see a significant difference in job outcomes, with participants being less likely to achieve tenure-track success and/or stay in neuroscience positions as compared with nonselected applicants, but this was not the case (see Table 3). Indeed, 10 participants became faculty members over this time period.

The qualitative data suggest that individual-level career productivity was impacted via the ongoing community-centric nature of the program, which created accountability, supported career momentum, and assisted in overcoming early-career challenges. Participants often discussed the role of the Mentoring Circles in creating accountability. For example, a participant from the second cohort wrote, "The Mentoring Circle has helped keep me on task and focused on both my research and on career development." Participants citing the longitudinal nature of the BRAINS program were also highly likely to note increases in their career productivity, such as writing more and submitting more grants. The longitudinal quality of the program allowed participants to maintain and develop skills they learned at the symposium while also deepening their connections to others in their network.

Respondents to the annual survey attested to increased connectivity. Both the networking activity and the mentoring activity indices significantly increased from time of application to time of first annual survey for both cohorts $(t(39)=-23.905$, $p<0.000$, and $t(39)=-3.331, p=0.002$, for networking and mentoring indices, respectively). Data from the open-ended survey questions suggest that participants attributed these changes in career-enhancing behaviors to BRAINS. In their responses to the open-ended survey questions, participants who noted that the symposium taught them the importance of networking also noted they had increased their networking activity. Similarly, participants who noted that the symposium taught them the importance of mentoring also discussed experiencing improved mentoring relationships and increased mentoring activity. A participant from the second cohort described this process:

If I had not attended BRAINS, I may have just withdrawn and not sought additional mentorship outside of my department or across the political lines in my department. Participating in BRAINS helped me to understand the value of having multiple mentors for different aspects of my career and development.
The establishment of a peer network began with increasing knowledge of the importance of networking and mentoring. In discussing their improved networking skills, increased networking activity, and improved mentoring relationships, participants were likely to also note how these skills and behaviors led them to develop collaborative relationships. One participant from the first cohort explained,

I have actually felt more informed so that I can speak with trainee peers and offer a more informed perspective. I have personally reached out to start 2 collaborations since BRAINS because I feel more aware of what I have to offer and what I can learn from others.

Thus, the networking and mentoring skills gained at BRAINS may lead to increased confidence, which in turn may lead to career-advancing behavior.

While the Mentoring Circles played a large role in addressing the participants' networking and mentoring needs, survey respondents were even more likely to discuss the role of interactions with the other participants, from relationships that began at the symposium to continued connections after the symposium. For example, a participant from the second cohort wrote, "The symposium created bonds between me and many like-minded scientists. I have become a mentor to some of them." Connections with the symposium panelists increased the participants' access to support, networking opportunities, and mentoring resources. In a few cases, participants directly gained new mentors via the panelists.

\section{Impacts on Career Experience}

The data also suggest that BRAINS participants experienced their careers differently since participating in the program. These effects are demonstrated in part through changes in career self-efficacy. As previously noted, career self-efficacy was assessed for 47 separate factors and then loaded onto seven self-efficacy indices. As shown in Table 4, six of the seven indices of self-efficacy significantly increased over time, suggesting higher levels of self-efficacy after BRAINS intervention.

On the open-ended survey responses, participants discussed the role of the professional development skills, the national network, and the ongoing nature of the program in increasing their career self-efficacy. The Mentoring Circles in particular were noted as assisting participants in maintaining and building upon the career self-efficacy that they gained at the symposium. For example, a participant from the second cohort wrote, 
TABLE 4. Mean index scores over time for participants

\begin{tabular}{|c|c|c|c|c|c|c|c|}
\hline & \multicolumn{2}{|c|}{ Mean index score } & \multicolumn{2}{|c|}{$\begin{array}{c}95 \% \text { Confidence } \\
\text { interval of the difference }\end{array}$} & \multicolumn{3}{|c|}{ Significance } \\
\hline & Application & Annual survey & Lower & Upper & $t$ & $d f$ & $p$ \\
\hline \multicolumn{8}{|l|}{ Self-efficacy indices } \\
\hline Research & 3.94 & 4.18 & 0.08 & 0.44 & 2.86 & 39 & 0.007 \\
\hline Management and administration & 3.49 & 4.04 & 0.34 & 0.77 & 5.18 & 39 & $<0.001$ \\
\hline Self-development & 3.59 & 3.99 & 0.20 & 0.57 & 4.16 & 39 & $<0.001$ \\
\hline Networking & 3.81 & 4.18 & 0.10 & 0.54 & 2.99 & 39 & 0.005 \\
\hline Mentoring & 3.68 & 4.27 & 0.44 & 0.81 & 6.81 & 39 & $<0.001$ \\
\hline Teaching and service & 4.11 & 4.17 & 0.10 & 0.23 & 0.77 & 39 & 0.449 \\
\hline Fulfillment and goals & 3.61 & 4.05 & 0.20 & 0.66 & 3.77 & 39 & 0.001 \\
\hline \multicolumn{8}{|l|}{ Connectivity and isolation indices } \\
\hline Network activity & 1.48 & 3.13 & 1.58 & 1.87 & -23.905 & 39 & $<0.001$ \\
\hline Mentoring activity & 3.44 & 3.80 & 0.12 & 0.50 & 3.331 & 39 & 0.002 \\
\hline Sense of belonging & 2.79 & 3.34 & 0.38 & 0.73 & 6.545 & 39 & $<0.001$ \\
\hline
\end{tabular}

Above all participation in BRAINS has given me the confidence in my abilities and a support system for those times when I'm not feeling as confident. Tapping into the support system has often made me aware of my abilities and resources [which] has allowed me to utilize my career development skills.

Survey respondents also described how the peer-mentoring aspect increased their networking confidence. For example, a participant from the first cohort wrote, "I realize that networking may be scary at times, but it ultimately helps in the long run. Meeting people in my similar situation and in places I might like to be has helped me to be more comfortable describing my science and meeting others." Thus, connecting with peers had a direct positive impact on career self-efficacy, which may have translated into positive behavioral changes.

Another participant from the second cohort described the impact BRAINS had on career self-efficacy via skill building, noting, "BRAINS has increased my confidence, particularly by describing key strategies that will help me build and maintain a successful, meaningful career in academia." This increase in knowledge and self-efficacy may then translate into careeradvancing behavior and increased career success, as in the case of this first cohort participant: "[The symposium] definitely helped in increasing my confidence and knowledge in what it takes to succeed in the academy. Since participating, I have gone on four job interviews and was offered two of the four positions." These results suggest that increased confidence and career self-efficacy created a positive-feedback loop among participants; they built upon their BRAINS involvement to experience early-career success, leading them to feel even more career self-efficacy and empowerment. A participant from the first cohort described this process:

I am much less hesitant [since BRAINS] to ask for help or an opinion. I have written a grant with input or collaborations set up across 5 labs. Instead of allowing my PI to reach out, I did all of the contacts and established what roles everyone could offer. Even if it doesn't get funded, I am proud of my ability to develop the proposal.

These early results suggest that the BRAINS program provides ongoing opportunities for impacts and supports partici- pants' career self-efficacy, which then translates into career-advancing behaviors, suggesting the interactions among the individual impacts within the BRAINS program theory.

In addition to increased career self-efficacy, the BRAINS program theory highlights three additional individual-level impacts to participants' career experience: reduced isolation, gained career perspective, and improved positive social identity. The sense of belonging index (a measure of reduction in isolation) showed statistically significant increases from time of application to first annual survey (Table 4).

In the open-ended survey responses, participants discussed the roles of the national network and peer cohorts of neuroscientists created through BRAINS in reducing their feelings of isolation. This community formation began at the symposium and continued through ongoing networking opportunities and peer mentoring. A participant from the second cohort described such impact of the national network and increased networking:

Following the BRAINS Symposium, I have connected with many peers from all over the United States who experience similar issues and problems regarding life/work balance issues, identity and cultural issues as a neuroscientist. The BRAINS program has increased my sense of belonging and support from various groups at different levels of my life and I am thankful for that.

One participant from the first cohort explained, "I feel that it has expanded the network of people I know in neuroscience at the same career stage. Before BRAINS, all I knew were established investigators and students I mentor." The Mentoring Circles not only allow academics at similar levels to connect but to develop relationships across career stages, as noted by a participant from the first cohort, "There is only one other member that is a mid to late stage postdoc so I am learning from the junior faculty and research faculty members about what it takes to progress." Participants at all career stages and from both cohorts spoke to the impact of the Mentoring Circles in providing ongoing support, advice, and feedback in regard to their careers.

Conversations about URM identity as part of the BRAINS program were also identified by participants as serving to 
reduce their feelings of isolation. A participant from the second cohort wrote, "I feel as though I have specific strategies and contacts (particularly program staff and BRAINS participants) to bounce ideas off that are specific to being an under-represented individual in neuroscience." Participants then were able to integrate these reflections into conversations external to the BRAINS program, as described by a participant from the first cohort: "I feel much more capable of explaining my feelings about [URM] status with my mentor as we discuss how all of my characteristics (publications, grant writing skills, etc.) will affect my career progression." BRAINS participants greatly valued the opportunity to explicitly discuss the scientific career experiences of individuals from URGs.

While the current survey instrument does not have quantitative metrics to assess gaining career perspective and improved positive social identity, data from the open-ended survey questions suggest a positive impact on these areas as well. The qualitative data suggest that the process of gaining career perspective began at the symposium, where shared perspectives gave participants insight into a long-term view of the academic career path. On the annual survey, many participants noted that, before their participation in BRAINS, they did not realize what they were missing in regard to professional development, what challenges they were facing, or what they needed in order to succeed. They reported that the symposium served to both inform participants about skills and activities they needed and to give them tools to address career challenges, thus improving their career perspectives. For example, one participant from the first BRAINS cohort wrote, "BRAINS didn't just tell me that I needed to do these things and that they were important. It has been explaining HOW to do these things." Sharing perspectives allowed the participants to learn new approaches to overcoming challenges in their careers. A participant from the first cohort wrote,

I learned a lot from participants and speakers. The discussions that we had not only made me feel better because we share the same problems or frustrations, they helped to change my points of view, and try different strategies to resolve old and new problems.

Thus, gaining career perspectives may have also led to career-advancing behavior.

As noted in the BRAINS program theory, conversations on careers and identities are a key component of the BRAINS program. In the open-ended survey responses, participants discussed how these conversations served to improve their positive social identity by normalizing adversity and thus encouraging individuals to no longer attribute their difficulties as being a sign that they do not belong in academia. Normalizing adversity also allowed participants to realize that these challenges can be overcome; as a participant from the first cohort wrote, "I appreciate knowing that what I feel and experience is not uncommon nor an unconquerable obstacle." Similarly, a participant from the second cohort described a key benefit of participating in the BRAINS program as "realizing that we all go thru [sic] similar steps in our professional development and that I have actually taken pretty good choices so far." In addition to normalizing feelings of adversity, these conversations also provided support and constructive feedback. Another participant from the first cohort noted, "[BRAINS] gave me a better sense of who my peers are and what challenges they are facing. It also gave me some practical advice for managing competing demands, and dealing with being a minority in science." Through normalizing adversity, these conversations about identity also had the ability to lead participants to revalue their own identities and location within biomedical and life sciences in a positive manner. For example, a participant from the second cohort explained, "The BRAINS workshops have increased my awareness on valuing my identity as a minority scientist." In the open-ended responses, participants attested to greatly valuing the opportunity to explicitly discuss the scientific career experiences of individuals from URGs. Thus, these conversations allow participants to recalibrate concerns and transform their anxiety about navigating careers into increased confidence and agency in pursuing their careers.

\section{DISCUSSION}

Social science research indicates that additional factors beyond scientific and professional skills are critical to support the persistence of individuals from URGs. The results presented here indicate that early-career neuroscientists from URGs have also struggled with isolation, sense of belonging, access to peer networks, self-efficacy, and accurate calibration of adversity and career outcomes expectations. BRAINS attempted to ameliorate these factors and address professional skills development and the cultivation of mentoring networks within the context of these factors.

While it is too soon to tell what the long-term impact of the BRAINS program will be on participants' career trajectories and persistence, we provide early results that suggest promising, positive career productivity; increased self-efficacy; stronger sense of belonging; and new perspectives on navigating careers for BRAINS participants. BRAINS intentionally cultivated community and network development, which led to repeated connections and personalized support. The enduring nature of the personal support from BRAINS may have provided a relevant and reliable mechanism by which participants continued to seek professional advice as new challenges emerged in their careers. Also, the ongoing aspect of the BRAINS mentoring approach created a community of colleagues who participants relied on, and this in turn may have reinforced their sense of belonging and connection to neuroscience. Moreover, as noted in the qualitative data, conversations at BRAINS about URG identity-specific topics helped normalize feelings of adversity and experiences as members of URGs. This normalization encouraged participants to no longer attribute their difficulties as being a sign that they do not belong in academia and to overcome challenges.

The findings presented here lend support to the SCCT, which states that career persistence is impacted by self-efficacy, outcome expectations, and personal goals. The increased self-efficacy resulting from participation in the BRAINS program led to behavioral changes, goal setting, and increased engagement within neuroscience. Many participants discussed that they not only increased their networking activity since BRAINS, but they also increased their engagement with neuroscience, found collaborators, and submitted more grant proposals. BRAINS may be influencing the career self-efficacy of participants, which in turn leads to a positive-feedback loop and 
improved career satisfaction and productivity (Cohen et al., 2009).

These early findings suggest that professional development interventions for postdoctoral fellows and early-career faculty that focus on skills acquisition might benefit from the addition of explicit community-building programmatic elements like those offered through the BRAINS program. Peer and multimentor research, coupled with our early findings, suggests that engaging in professional development within a community context creates a shared experience that increases the depth of the professional development and connection to others and leads to changes in behavior and increased productivity and intention to persist. By intentionally cultivating community among the BRAINS leadership team, early-career participants, and senior scientists, BRAINS may provide participants with a mechanism to help sustain the impact of the program and continue to increase their social and navigational capital (e.g., Yosso, 2005; Manson, 2016). Such ongoing connections are atypical of stand-alone professional development workshops in which individuals are left to figure out skills implementation on their own after the workshop has concluded. The ongoing BRAINS community provides support to participants as they dissect, evaluate, examine, and try the suggestions and ideas from the BRAINS activities.

There are several limitations to this work as well as areas for further investigations. First, while the quantitative data show that BRAINS participants experienced statistically significant increases on a number of measures of career self-efficacy, networking activity, mentoring activity, and sense of belonging, the data presented here lack a comparison group (beyond the job position analysis); thus, it is difficult to unambiguously isolate the impact of BRAINS. Traditional measures of productivity, such as publications and obtaining grants, occur on a longer timescale than the program's lifetime thus far. We are currently addressing this via a curriculum vitae analysis of participants and nonselected applicants, measuring changes in traditional metrics of academic success, such as articles published, presentations given, and grants received. Second, additional measures should be developed to determine the impact of gaining career perspectives and developing positive social identity on participants' careers. The sense of belonging metrics could also be further refined to build on validated sense of belonging metrics (e.g., Goodenow, 1993; Hagerty and Patusky, 1995; Hoffman et al., 2003). Third, while participant responses to the openended survey questions provide qualitative support for the BRAINS program theory, additional work should be done to fully validate the framework and metrics used. In particular, work is needed to develop and validate metrics, such as self-efficacy, sense of belonging, and mentoring relationship, for the postdoctoral and junior faculty career stages (Pfund et al., 2016).

While we did not assess the impact of particular program features on participant impacts and outcomes here, we suggest that future work examine the potential causal relationships among the features of BRAINS highlighted in the BRAINS program theory and outcomes. Also, the qualitative data in particular suggest complicated interactions among the individual impact factors in the BRAINS program theory and among the program features, individual impacts, and career impacts. Additional research should be conducted to better understand the interaction between these factors to better understand the impact of both individual elements and combinations of elements (e.g., Byars-Winston et al., 2010). These early results also may inform future work on developing metrics of successful mentoring and different types of mentoring relationships (Pfund et al., 2016). Enrolling additional cohorts of participants in the BRAINS program will offer greater statistical power in our analyses and deeper analysis of these impacts.

Certainly, many factors contributed to the successes of BRAINS participants. Nevertheless, the qualitative data shown here allow BRAINS participants to speak directly to the role of the BRAINS program in their career development, self-efficacy, and job satisfaction. By establishing peer networks, sharing perspectives on navigating careers, providing ongoing professional development opportunities, and explicitly addressing concerns of scientists from URGs, the BRAINS program is able to positively impact participants' career self-efficacy and intentions to persist. Aspects of this ongoing, community-centric model of professional development could be adopted by other programs to diversify the biomedical workforce and support the advancement and persistence of diverse scientists.

\section{ACKNOWLEDGMENTS}

The BRAINS program is funded through an NINDS NIH grant 1R25NS076416. We are indebted to Sapna Cheryan and three anonymous reviewers for comments on earlier versions of this article. We are also grateful to the BRAINS community: our advisory boards, senior panelists, and, most of all, our participants.

\section{REFERENCES}

Agho AO, Price JL, Mueller CW (1992). Discriminant validity of measures of job satisfaction, positive affectivity and negative affectivity. $\mathrm{J}$ Occup Organ Psychol 65, 185-195

Allen-Ramdial S-AA, Campbell AG (2014). Reimagining the pipeline: advancing STEM diversity, persistence, and success. BioScience 64, 612-618.

Austin AE, Rice RE (1998). Making tenure viable: listening to early career faculty. Am Behav Sci 41, 736-754.

Bandura A (1977). Self-efficacy: toward a unifying theory of behavioral change. Psychol Rev 84, 191-215.

Baugh SG, Scandura TA (1999). The effect of multiple mentors on protege attitudes toward the work setting. Soc Behav Pers 14, 503-521.

Betz NE (2007). Career self-efficacy: exemplary recent research and emerging directions. J Career Assess 15, 403-422.

Blackburn RT, Chapman DW, Cameron SM (1981). "Cloning" in academe: mentorship and academic careers. Res High Educ 15, 315-327.

Boice R (1992). The New Faculty Member: Supporting and Fostering Professional Development, San Francisco: Jossey-Bass.

Boice R (2000). Advice for New Faculty Members, Needham, MA: Allyn \& Bacon.

Brault MW (2012). Americans with Disabilities: 2010 (Publication No. P70131), Washington, DC: U.S. Census Bureau. Www.census.gov/prod/ 2012pubs/p70-131.pdf (accessed 12 May 2016).

Brown SD, Lent RW (1996). A social cognitive framework for career choice counseling. Career Dev Q 44, 354-366.

Byars-Winston A, Estrada Y, Howard C, Davis D, Zalapa J (2010). Influence of social cognitive and ethnic variables on academic goals of underrepresented students in science and engineering: a multiple-group analysis. J Couns Psychol 57, 205-218.

Byars-Winston A, Fouad NA (2008). Math and science social cognitive variables in college students: contributions of contextual factors in predicting goals. J Career Assess 16, 425-440. 
Byars-Winston A, Gutierrez B, Topp S, Carnes M (2011). Integrating theory and practice to increase scientific workforce diversity: a framework for career development in graduate research training. CBE Life Sci Educ 10, 357-367.

Carr PL, Palepu A, Szalacha L, Caswell C, Inui T (2007). "Flying below the radar": a qualitative study of minority experience and management of discrimination in academic medicine. Med Educ 41, 601-609.

Chemers MM, Zurbriggen EL, Syed M, Goza BK, Bearman S (2011). The role of efficacy and identity in science career commitment among underrepresented minority students. J Soc Issues 67, 469-491.

Cohen GL, Garcia J, Purdie-Vaughns V, Apfel N, Brzustoski P (2009). Recursive processes in self-affirmation: intervening to close the minority achievement gap. Science 324, 400-403.

Congressional Commission on the Advancement of Women and Minorities in Science, Engineering, and Technology Development. (2009). Land of Plenty: Diversity as America's Competitive Edge in Science, Engineering, and Technology. www.nsf.gov/pubs/2000/cawmset0409/cawmset_0409 .pdf (accessed 24 May 2016).

Corbin JM, Strauss A (1990). Grounded theory research: procedures, canons, and evaluative criteria. Qual Soc 13, 3-21.

De Janasz SC, Sullivan SE (2004). Multiple mentoring in academe: developing the professorial network. J Vocat Behav 263-283.

Estrada-Hollenbeck M, Woodcock A, Hernandez PR, Schultz P (2011). Toward a model of social influence that explains minority student integration into the scientific community. J Educ Psychol 103, 206-222.

Fraga LR, Jones J, Joseph R, Rodriguez NE (2010). Innovations in faculty empowerment: women investigating race, ethnicity, and difference (WIRED). Paper presented at the Keeping Our Faculties of Color Symposium, Faculty Diversity in Higher Education: An Agenda for Change, University of Minnesota, Minneapolis, November 2010.

Futrell MH, Walter AB (2001). Diversity in higher education. Educ Adm Abstr $36,274-408$

Gappa JM (2002). Academic careers for the 21st century: more options for new faculty. In: Higher Education: Handbook of Theory and Research vol. 17, ed. WG Tierney and JC Smart, Norwell, MA: Kluwer Academic.

Gibbs KD Jr, Griffin KA (2013). What do I want to be with My PhD? The roles of personal values and structural dynamics in shaping the career interests of recent biomedical science PhD graduates. CBE Life Sci Educ 12, $711-$ 723.

Goodenow C (1993). The psychological sense of school membership among adolescents: scale development and educational correlates. Psychol Sch 30, 79-90

Gorsuch RL (1983). Factor Analysis, 2nd ed., Hillsdale, NJ: Lawrence Erlbaum Associates.

Hagerty BMK, Patusky K (1995). Developing a measure of sense of belonging J Nurs Res 44, 9-13.

Haring MJ (1999). The case for a conceptual base for minority mentoring programs. Peabody J Educ 74(2), 5-14.

Higgins MC (2000). The more, the merrier? Multiple developmental relationships and work satisfaction. J Manag Dev 19, 277-296.

Hoffer TB, Dugoni BL, Sanderson AR, Sederstrom S, Welch V, Guzman-Barron I, Brown S (2002). Doctorate Recipients from United States Universities Summary Report 2001, Chicago: NORC at the University of Chicago

Hoffer TB, Hess M, Welch V Jr, Williams K (2007). Doctorate Recipients from United States Universities: Summary Report 2006, Chicago: NORC at the University of Chicago.

Hoffer TB, Sederstrom S, Selfa L, Welch V, Hess M, Brown S, Reyes S, Webber K, Guzman-Barron I (2003). Doctorate Recipients from United States Universities: Summary Report 2002, Chicago: NORC at the University of Chicago.

Hoffer TB, Selfa L, Welch V Jr, Williams K, Hess M, Friedman J, Reyes SC, Webber K, Guzman-Barron I (2004). Doctorate Recipients from United States Universities: Summary Report 2003, Chicago: NORC at the University of Chicago.

Hoffer TB, Welch V Jr, Webber K, Williams K, Lisek B, Hess M, Loew D, Guzman-Brown I (2006). Doctorate Recipients from United States Universities: Summary Report 2005, Chicago: NORC at the University of Chicago.
Hoffer TB, Welch V Jr, Williams K, Hess M, Webber K, Lisek B, Loew D, Guzman-Barron I (2005). Doctorate Recipients from United States Universities: Summary Report 2004, Chicago: NORC at the University of Chicago.

Hoffman M, Richmond J, Morrow J, Salomone K (2003). Investigating "sense of belonging" in first-year college students. J Coll Stud Ret 4, 227-256.

Jacelon CS, Zucker DM, Staccarini J-M, Henneman EA (2003). Peer mentoring for tenure-track faculty. J Prof Nurs 19, 335-338.

Jaschik S (2014, November 3). Missing minority Ph.D.s. Inside Higher Ed. www.insidehighered.com/news/2014/11/03/study-finds-serious-attrition -issues-black-and-latino-doctoral-students.

Kelman HC (1958). Compliance, identification, and internalization: three processes of attitude change. J Conflict Resolut 2, 51-60.

Kelman HC (2006). Interests, relationships, identities: three central issues for individuals and groups in negotiating their social environment. Annu Rev Psychol 57, 1-26.

Lent RW, Brown SD (1996). Social cognitive approach to career development: an overview. Career Dev Q 44, 310-321.

Lent RW, Brown SD, Hackett G (2000). Contextual supports and barriers to career choice: a social cognitive analysis. J Couns Psychol 47, 36-49.

Lent RW, Brown SD, Sheu H-B, Schmidt J, Brenner BR, Gloster CS, Wilkins G, Schmidt LC, Lyons H, Treistman D (2005). Social cognitive predictors of academic interests and goals in engineering: utility for women and students at historically black universities. J Couns Psychol 52, 84-92.

MacCallum RC, Widman KF, Zhang S, Hong S (1999). Sample size in factor analysis. Psychol Methods 4, 84-89.

Manson SM (2016). Early-stage investigators and institutional interface: importance of organization in the mentoring culture of today's universities. AIDS Behav 1-7.

McLeod PL, Lobel SA, Cox TH Jr (1996). Ethnic diversity and creativity in small groups. Small Group Res 27, 248-264.

Milliken FJ, Martins LL (1996). Searching for common threads: understanding the multiple effects of diversity in organizational groups. Acad Manage Rev 21, 402-433.

Milo R, Schuldiner M (2009). Weizmann Young PI Forum: the power of peer support. Mol Cell 36, 913-915.

National Center for Science and Engineering Statistics (2009). Doctorate Recipients from U.S. Universities: Summary Report 2007-08. Arlington, VA.

National Center for Science and Engineering Statistics (2012a). Doctorate Recipients from U.S. Universities: 2010 (Publication No. NSF 12-305), Arlington, VA: National Science Foundation.

National Center for Science and Engineering Statistics (2012b). Doctorate Recipients from U.S. Universities: 2011 (Publication No. NSF 13-301) Arlington, VA: National Science Foundation.

National Center for Science and Engineering Statistics (2014a). Doctorate Recipients from U.S. Universities: 2012 (Publication No. NSF 14-305), Arlington, VA: National Science Foundation

National Center for Science and Engineering Statistics (2014b). Doctorate Recipients from U.S. Universities: 2013 (Publication No. NSF 15-304) Arlington, VA: National Science Foundation.

National Institutes of Health (NIH) (n.d.a). Department of Health and Human Services Web page http://grants.nih.gov/grants/guide/rfa-files/RFA -RM-13-017.html.

NIH (n.d.b). Research Training and Career Development: Institutional Training Grants. https://researchtraining.nih.gov/programs/training-grants $?$ CFID $=35507291 \&$ CFTOKEN $=98414 f 8 c b 45 f e 958-297 E D D 1 A-5056$ -9439-7E53E3D3CA53511A (accessed 18 May 2016).

NIH (n.d.c). Research Training and Career Development: Research Career Development Awards. https://researchtraining.nih.gov/programs/career -development (accessed 18 May 2016).

National Science Foundation (NSF) (2004). Women, Minorities, and Persons with Disabilities in Science and Engineering: 2004 (Publication No. NSF 04-317), Arlington, VA

NSF (2007). Women, Minorities, and Persons with Disabilities in Science and Engineering: 2007 (Publication No. NSF 07-315), Arlington, VA.

NSF (2009). Women, Minorities, and Persons with Disabilities in Science and Engineering: 2009 (Publication No. NSF 09-305), Arlington, VA. 
NSF (2010). Doctorate Recipients from U.S. Universities: 2009 (Publication No. NSF 11-306), Arlington, VA: www.nsf.gov/statistics/sed/2009/ SED_2009.zip (accessed 19 may 2016).

NSF (2011). Women, Minorities, and Persons with Disabilities in Science and Engineering: 2011 (Publication No. NSF 11-309), Arlington, VA.

NSF (2013). Women, Minorities, and Persons with Disabilities in Science and Engineering: 2013 (Publication No. NSF13-304), Arlington, VA.

Niemeier DA, Smith V (2005). Building careers, transforming institutions: underrepresented women and minorities, leadership opportunities, and institutional networking. J Women Minor Sci Eng 11, 181-196.

Nivet MA, Taylor VS, Butts GC, Strelnick AH, Herbert-Carter J, Fry-Johnson YW, Smith QT, Rust G, Kondwani K (2008). Diversity in academic medicine no. 1 case for minority faculty development today. Mt Sinai J Med 75, 491-498.

Page SE (2007). The Difference: How the Power of Diversity Creates Better Groups, Firms, Schools, and Societies, vol. 11, Princeton, NJ: Princeton University Press.

Patton S (2014, October 27). Black man in the lab: why do so few black men earn STEM degrees? The reasons, and the remedies, go beyond numbers. Chron High Educ.

Pfund C, Byars-Winston A, Branchaw J, Hurtado S, Eagan K (2016). Defining attributes and metrics of effective research mentoring relationships. AIDS Behav 1-11.

Phinney JS (1992). The Multigroup Ethnic Identity Measure: a new scale for use with diverse groups. J Adoles Res 7, 156-176.

Plaut V (2014). Models of success in the academy. In: The Truly Diverse Faculty: New Dialogues in American Higher Education, ed. SA Fryberg and EJ Martinez, New York: Palgrave Macmillan.

Sandler BR, Hall RM (1986). The Campus Climate Revisited: Chilly for Women Faculty, Administrators, and Graduate Students, Washington, DC: Association of American Colleges.

Smith JW, Smith WJ, Markham SE (2000). Diversity issues in mentoring academic faculty. J Career Dev 251-262.

Stanley CA, Lincoln YS (2005). Cross-race faculty mentoring. Change 37, 44-50.
Stephens NM, Hamedani MarYam G, Destin M (2014). Closing the social-class achievement gap: a difference-education intervention improves firstgeneration students' academic performance and all students' college transition. Psychol Sci 25, 943-53.

Sved AF (2013). Report of Survey of Neuroscience Graduate, Postdoctoral, \& Undergraduate Programs (Academic Year 2010-2011). Retrieved from Society for Neuroscience. www.sfn.org/ /media/SfN/Documents/ Professional\%20Development/NDP/SurveyReportAY20102011.ashx.

Tierney WG, Bensimon EM (1996). Promotion and Tenure: Community and Socialization in Academe, vol. 98, Albany: State University of New York Press.

Trower CA, Bleak JL (2004). Study of New Scholars. Institutional Type: Statistical Report, Cambridge, MA: Harvard Graduate School of Education.

Turner CSV, González JC, Wood JL (2008). Faculty of color in academe: what 20 years of literature tells us. J Divers High Educ 1, 139-168.

U.S. Census Bureau (2014). National Characteristics: Vintage 2014. www .census.gov/popest/data/national/asrh/2014/index.html (accessed 24 May 2016).

Walton GM, Cohen GL (2011). A brief social-belonging intervention improves academic and health outcomes of minority students. Science 331, 14471451.

Williams SN, Thakore BK, McGee R (2016). Coaching to augment mentoring to achieve faculty diversity: a randomized controlled trial. Acad Med 91, 1128-1135.

Working Group on Diversity in the Biomedical Research Workforce (2012). Diversity in the Biomedical Research Workforce Working Group Report. Retrieved from National Institutes of Health: http://acd.od.nih.gov/ Diversity\%20in\%20the\%20Biomedical\%20Research\%20Workforce\%20 Report.pdf.

Wunsch MA (1993). Mentoring probationary women academics: a pilot programme for career development. Stud High Educ 18, 349-362.

Yen JW, Quinn K, Carrigan C, Litzler E, Riskin EA (2007). The ADVANCE mentoring-for-leadership lunch series of women faculty in STEM at the University of Washington. J Women Minor Sci Eng 191-206.

Yosso TJ (2005). Whose culture has capital? A critical race theory discussion of community cultural wealth. Race Ethn Educ 8(1), 69-91. 